\title{
The Study of Affective Value in Educational Video Production Style Using Kansei Engineering Method
}

\author{
Nur Faraha Bte Hj. Mohd. Naim, and Ag. Asri Ag. Ibrahim
}

\begin{abstract}
This paper presents the emotional responses among higher institution learners towards the production style of an educational video. The video design concepts for each production style were categorized into three sections, non-linear video with visual effects (interactive video mobile-learning), linear video with visual effects (green screen) and linear video with no visual effects (screencast). The Kansei Engineering approach was used to measure the learners' emotion reaction on each of the production style. Through Kansei Engineering method, the outcomes presented variance of active and passive emotion reaction towards the production style, difference feelings responses caused by the video design, whereas at the end most learners agreed that the inclusion of interactivity and aesthetics in video design will increase their motivation to learn from the educational video.
\end{abstract}

Index Terms - Educational videos, video design, production style, Kansei engineering, affective value, mobile-learning.

\section{INTRODUCTION}

The educational video is used as a secondary medium for instructors to deliver an audio-visual education and tutorials to learners. It is an essential operative in teaching and learning $(T \& L)$ as an alternative medium to leverage learners' affective value. With the existence of online video platform such as YouTube, deploying the educational videos to learners has become much easier, and the educational videos are accessible for learners. According to Kaur in the New Straits Times website, Google Survey stated YouTube is a popular platform for Malaysian to watch the online videos in comparison to other nation [1]. Thus, educational video deployment through the YouTube platform is multiplying over time.

\section{A. Educational Video Production Style}

Concerning on the production style of educational video, Vieira, Lopes, and Soares stated that the video interface with significant value in pedagogy goal and creative utilization of the educational video can strongly motivate learners to embrace knowledge [2]. Hansch, Hillers, McConachie, Newman, Schildhauer, and Schmidt agreed with Vieira et al. that the pedagogy goal can be influenced by visual aesthetics and production value of a video though depending on the production styles and capability [3]. Fitzgibbon mentioned about the 'interactive-video-conferencing' will not be effective if there is no proactive plan from the instructor [4].

Manuscript received February 19, 2020; revised May 10, 2020.

Nur Faraha Bte Hj. Mohd. Naim and Ag. Asri Ag. Ibrahim are with the Faculty of Computing and Informatics, Universiti Malaysia Sabah, Jalan UMS, 88400 Kota Kinabalu, Malaysia (e-mail: faraha.naim@ums.edu.my, awgasri@ums.edu.my).
Therefore, in retrospect to the above statements, the production style of a video should be considered in a video design to influence the affective value.

Affective value reflects on the aspect of learners' feelings about the production style of an educational video. The way learners' emotions responded when utilizing the educational videos can be varied based on the differences in production style. Vieira et al. issued the video design consideration based on the feedback from learners, such as making short videos, avoid the abrupt video transitions, provide interactive links and highlights, summarize the contents and create click access to the important parts [2]. Denning stressed on the oversimplification or excessive use of visual effects on videos are the imperative components to look at [5]. The goal of examining the affective value is to scale down the lack of enthusiasm and heighten the devotion in self-learning among the learners through emotions as motivation.

Production style can be in the form of linear video and non-linear video based on the video design aspect. Brame pointed out the cognitive load, engagement, and active learning as elements needed in designing an educational video. He stated that the segmentation into short videos (chunk information) could optimize the cognitive load and encourage students to stay engaged, furthermore, applying interactive features in a video can create active learning among learners [6]. The video length should be a factor in educational video production since the video length impacted learners' consideration to stay engaged with the video [7]. Thus, by segmenting the video in the timeline through time points feature may heighten the positive emotions.

Foremost, careless video design can yield to negative response and dissatisfaction among learners. Referring to Kies, Williges, and Rosson, low satisfaction on educational video will decrease students' enthusiasm in learning, thus, impact on students' attrition rate [8]. Therefore, finding the learners' reaction through their emotion is prudent to measure the response of the feelings (affective value) in production style. Two problems may cause disengaged among learners - the video arrangement and visual aesthetics in a production style.

A nationwide survey was conducted in 2018 by Kaltura about the prospect of interactive video possibly will play an important role in the forthcoming education, with $97 \%$ of respondents' feedbacks reported agreed [9]. An experiment was conducted during the laboratory sessions where the students watch the video tutorial through iPads, the way they behaved shows that as if they were searching for the convenience and the availability of interactive feature in a video [10]. Thereof, an educational video for higher institutions needs to be engaging and attractive enough for 
learners to stay tuned and utilize the video as their alternative method to studies. Hence, the thereof thought leads to finding the exact sensibility of production style that can evoke feelings engagement as central motivation to self-learning when using the video.

\section{B. Kansei Engineering Approach}

The feelings measurement can be done through the Kansei Engineering Approach, a method that is known to be widely used to measure human psychology feelings. Mitsuo Nagamachi explained that Kansei Engineering is a translating technology that conveys consumers emotions as a criterion for product design [11]. METI refers to Kansei Engineering as 'commitment' and 'consideration' values given by the manufactures to the users that cause the users to appreciate the product even more [12]. Levy stated that Kansei Engineering (KE) has commanded numerous market success, product research disciplines, and innovations [13]. It is because that $\mathrm{KE}$ create products and designs that satisfy users by assimilating human psychological feelings into design elements. Aside from the marketing aspect, Kansei Engineering can be used as a tool to facilitate the instructional designers in designing their learning materials that could evoke positive emotions [14]. Hazlina Adnan and Fauziah Redzuan used the Kansei Engineering method to assert the design elements in video-based learning materials on YouTube that could elicit students' emotions. They manage to find 5 pillars of Kansei semantic space of emotions; professional-motivated, fun, joking-humorous, deceptive and puzzled, confirming the e-learning video can elicit specific emotions based on these pillars for design elements in video-based learning materials [15]. Sakhllah Zubir and Fauziah Redzuan expand the study of design elements using the Kansei engineering on mobile-learning and found 5 pillars that are fun-motivated, learnable, challenging, preoccupied and engaged [16].

The motivation of this research study is to assess the significance of educational video production style toward learners' engagement. Hence, the Kansei Engineering methodology is used to discover the correlation between human emotion (affective value) and production style. The production style divided into three sections; non-linear video with visual effects (interactive video mobile-learning), linear video with visual effects (green screen) and linear video with no visual effects (screencast). The learners' feeling could be dissimilar and varied in proportion to the distinctive video design concept.

\section{MethodolOGY}

The experiment was conducted in a class with one hundred and fifty college and university students as the respondents. The one hundred and fifty students were then divided into three groups (Group A, Group B, and Group C) to test the products. Each of the group consists of fifty students. As samples for this experiment, three production style - Product A: Pocket IVML is a combination of Green Screen, Animation and Screencast (non-linear video with visual effects) will be used in Group A, Product B: Green Screen (linear video with visual effects) will be used in Group B and
Product C: Screencast (linear video with no visual effects) will be used in Group $\mathrm{C}$

All these samples from each group were used to extract the emotional responses from students. Fig. 1 shows the affective value treatment. The statistic package used in analysing the data are Factor Analysis (KMO), PCA Extraction Method (Communalities Analysis), SPSS Descriptive Statistics (Frequencies), and One-Way ANOVA.

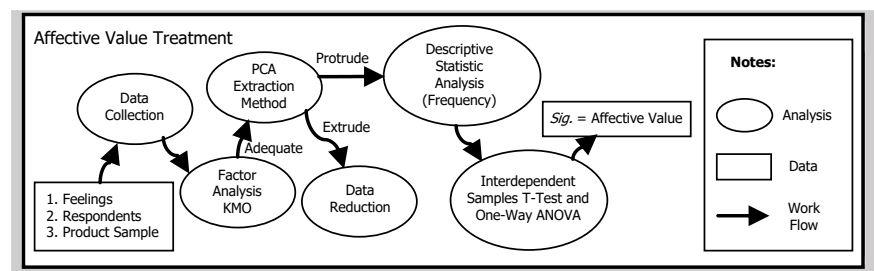

Fig. 1. Module analytical technique design framework.

The measurement of 1 to 5 rating scale for each emotion indicates how they felt about the production style as shown in Fig. 2 below.

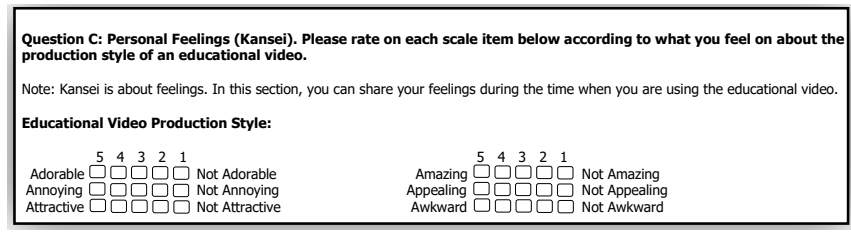

Fig. 2. Feelings measurement in Kansei methodology.

\section{ANALYTICAL TECHNIQUES}

\section{A. Data Reduction Using Kaiser-Meyer-Olkin (KMO)}

Table I, II and III denotes the Kaiser-Meyer-Olkin (KMO) and Bartlett's Test Results. The KMO was used to test the data sample and verify adequacy value within the variables. The correlation range of KMO is between 0 to 1 value. The considerably adequate variable value for $\mathrm{KMO}$ correlation is above $0.60-0.70$, which indicated that the Factor Analysis is appropriate and acceptable for these data [17]. Any value that is below or equal to 0.5 is considered as poor and should be removed from the list whilst the value closest to 1 is considered as good data.

The Communalities Factor Analysis in Data Reduction SPSS was used to measure and analyse the potential emotional factors. The communalities range is from 0 to 1 where the value 1 is inferring to high variance whilst the 0 value infers to no variance in variables. The communalities are consisting of initial and extraction where the initial value was assumed as 1 and the extraction is the variance number that the extraction of the variable is made. Hence, if the extraction value is equal to or less than 0.5 in which depicted as low communalities, then the variable should be removed from the analysis.

\section{- Potential Emotion Factors for Product A: IVML} (Non-Linear Video with Visual Effects)

Based on Kaiser recommendation, the value between 0.50 to 0.70 are considered average [18] and the KMO and Bartlett's Test significance value must below 0.05 for correlated variables happened. In Communalities Extraction Method: Principal Component Analysis, any variables that 
are less than 0.5 are considered as low communalities and should be dropped from the analysis, however, for this KMO test all feelings variables are adequate. Referring to Table I, the KMO test is 0.681 for Product A: IVML (Non-Linear Video with Visual Effects), therefore, the feelings variables used for the test are moderately adequacy.

TABLE I: KMO AND BARTLETT'S TEST FOR PRODUCT A: IVML (NON-LINEAR VIDEO WITH VISUAL EFFECTS)

\begin{tabular}{|c|c|c|}
\hline \multicolumn{2}{|c|}{ Kaiser-Meyer-Olkin Measure of Sampling Adequacy. } & .681 \\
\hline Bartlett's Test of Sphericity & Approx. Chi-Square & 765.235 \\
\hline & Df & \\
\hline & Sig. & \\
\hline
\end{tabular}

- Potential Emotion Factors for Product B: Green Screen (Linear Video with Visual Effects)

Referring to the Table II below, the KMO test is 0.666 for Product B: Green Screen (Linear Video with Visual Effects) and the p-value is less than 0.001 is highly significant, therefore, the feelings variables used for the test are moderately adequacy. In Communalities Extraction Method: Principal Component Analysis, any variables that are less than 0.5 are considered as low communalities and should be dropped from the analysis, however, for this KMO test all feelings variables are adequate.

TABLE II: KMO AND BARTLETT'S TEST FOR PRODUCT B: GREEN SCREEN (LINEAR VIDEO WITH VISUAL EFFECTS)

\begin{tabular}{|c|c|c|}
\hline \multicolumn{2}{|c|}{ Kaiser-Meyer-Olkin Measure of Sampling Adequacy. } & .666 \\
\hline Bartlett's Test of Sphericity & Approx. Chi-Square & 635.792 \\
\hline & Df & 300 \\
\hline & Sig. & .000 \\
\hline
\end{tabular}

- Potential Emotion Factors for Product C: Screencast (Linear Video with No Visual Effects)

Referring to the Table III, the KMO test is 0.665 for Product C: Screencast (Linear Video with No Visual Effects) and the p-value is less than 0.001 is highly significant, therefore, the feelings variables used for the test are moderately adequacy. In Communalities Extraction Method: Principal Component Analysis, any variables that are less than 0.5 are considered as low communalities and should be dropped from the analysis, however, for this KMO test all feelings variables are adequate.

TABLE III: KMO AND BARTLETT'S TEST FOR PRODUCT C: SCREENCAST (LINEAR VIDEO WITH NO VISUAL EFFECTS)

\begin{tabular}{|c|c|c|}
\hline \multicolumn{2}{|c|}{ Kaiser-Meyer-Olkin Measure of Sampling Adequacy. } & .665 \\
\hline \multirow[t]{3}{*}{ Bartlett's Test of Sphericity } & Approx. Chi-Square & 754.131 \\
\hline & Df & 300 \\
\hline & Sig. & 然. \\
\hline
\end{tabular}

\section{B. Descriptive Statistics: Frequencies}

Following are the results of descriptive analysis frequencies extracted from students for the three production styles of educational videos - Product A: Pocket IVML (non-linear video with visual effects), Product B: Green Screen (linear video with visual effects) and Product C: Screencast (linear video with no visual effects).
- Product A: Pocket IVML (Non-Linear Video with Visual Effects):

Table IV denotes positive emotional responses from students. The results justify that this type of production style almost succeeded in stimulating the positive feelings among the students involved, with two out of twenty-five feelings have resulted in Moderate level, thus, confirming a positive influence of affective value in Product A: Pocket IVML (Non-Linear Video with Visual Effects).

TABLE IV: PRODUCT A - POCKET IVML (NON-LINEAR VIDEO WITH VISUAL EFFECTS)

\begin{tabular}{|c|c|c|c|c|}
\hline \multicolumn{5}{|c|}{ Results Generated from Descriptive Analysis Frequency } \\
\hline $\begin{array}{l}\text { Types of } \\
\text { Feelings }\end{array}$ & Level & $\begin{array}{c}\text { Frequency } \\
\text { of } \\
\text { Respondents }\end{array}$ & $\begin{array}{c}\text { Total } \\
\text { Rating } \\
\text { Scale }\end{array}$ & $\begin{array}{c}\text { Mean } \\
\text { Value } \\
(\mathbf{N})\end{array}$ \\
\hline Annoying & Not Annoying & 28 & 89 & 1.78 \\
\hline Appealing & $\begin{array}{c}\text { Almost } \\
\text { Appealing }\end{array}$ & 21 & 181 & 3.62 \\
\hline Attractive & $\begin{array}{c}\text { Almost } \\
\text { Attractive }\end{array}$ & 23 & 191 & 3.82 \\
\hline Awkward & Not Awkward & 19 & 117 & 2.34 \\
\hline Boring & Not Boring & 22 & 105 & 2.10 \\
\hline Convenient & $\begin{array}{c}\text { Almost } \\
\text { Convenient }\end{array}$ & 19 & 184 & 3.68 \\
\hline Comfortable & $\begin{array}{c}\text { Almost } \\
\text { Comfortable }\end{array}$ & 25 & 195 & 3.90 \\
\hline Comprehended & $\begin{array}{c}\text { Almost } \\
\text { Comprehended }\end{array}$ & 17 & 174 & 3.48 \\
\hline Confusing & Not Confusing & 16 & 124 & 2.48 \\
\hline Cool & Almost Cool & 20 & 199 & 3.98 \\
\hline Creative & Creative & 24 & 216 & 4.32 \\
\hline Fun & $\begin{array}{l}\text { Almost Fun, } \\
\text { Fun }\end{array}$ & $\begin{array}{l}19 \\
19\end{array}$ & 204 & 4.08 \\
\hline Impressive & $\begin{array}{c}\text { Almost } \\
\text { Impressive }\end{array}$ & 19 & 201 & 4.02 \\
\hline Interesting & Interesting & 26 & 216 & 4.32 \\
\hline Irritating & Moderate & 19 & 130 & 2.60 \\
\hline Lost & Not Lost & 20 & 106 & 2.12 \\
\hline Neat & Moderate & 16 & 160 & 3.20 \\
\hline Necessary & $\begin{array}{l}\text { Moderate, } \\
\text { Almost } \\
\text { Necessary, } \\
\text { Necessary }\end{array}$ & $\begin{array}{l}16 \\
16 \\
16\end{array}$ & 195 & 3.90 \\
\hline Professional & Professional & 23 & 211 & 4.22 \\
\hline Refreshing & $\begin{array}{c}\text { Almost } \\
\text { Refreshing, } \\
\text { Refreshing }\end{array}$ & $\begin{array}{l}17 \\
17\end{array}$ & 194 & 3.88 \\
\hline Satisfied & $\begin{array}{c}\text { Almost } \\
\text { Satisfied }\end{array}$ & 20 & 191 & 3.82 \\
\hline Simple & Simple & 21 & 201 & 4.02 \\
\hline Troublesome & $\begin{array}{c}\text { Not } \\
\text { Troublesome }\end{array}$ & 25 & 101 & 2.02 \\
\hline User-Friendly & User-Friendly & 26 & 210 & 420 \\
\hline Waste of Time & $\begin{array}{c}\text { Not Waste of } \\
\text { Time }\end{array}$ & 31 & 91 & 1.82 \\
\hline
\end{tabular}

\section{- Product B: Green Screen (Linear Video with Visual} Effects)

Table V shows the counterbalance of 'being neutral to positive emotion' responses from students. The results justify that this type of production style does not quite manage to trigger positive feelings among the students involved as the felt a bit more inclined to feeling moderate, with thirteen out of twenty-five feelings have resulted in Moderate level, thus, confirming the less influence of affective value in Product B: Green Screen (Linear Video with Visual Effects). 
TABLE V: PRODUCT B - GREEN SCREEN (LINEAR VIDEO WITH VISUAL EFFECTS)

\begin{tabular}{|c|c|c|c|c|}
\hline \multicolumn{6}{|c}{ Results Generated from Descriptive Analysis Frequency } \\
\hline $\begin{array}{c}\text { Types of } \\
\text { Leelings }\end{array}$ & $\begin{array}{c}\text { Frequency } \\
\text { of } \\
\text { Respondents }\end{array}$ & $\begin{array}{c}\text { Total } \\
\text { Rating } \\
\text { Scale }\end{array}$ & $\begin{array}{c}\text { Mean } \\
\text { Value } \\
\text { (N) }\end{array}$ \\
\hline Annoying & Not Annoying & 16 & 111 & 2.22 \\
\hline Appealing & Moderate & 24 & 173 & 3.46 \\
\hline Attractive & Moderate & 23 & 170 & 3.40 \\
\hline Awkward & Moderate & 17 & 117 & 2.34 \\
\hline Boring & Less Boring & 17 & 114 & 2.28 \\
\hline Convenient & Moderate & 23 & 167 & 3.34 \\
\hline Comfortable & $\begin{array}{c}\text { Almost } \\
\text { Comfortable }\end{array}$ & 20 & 191 & 3.82 \\
\hline Comprehended & Moderate & 24 & 158 & 3.16 \\
\hline Confusing & Moderate & 17 & 133 & 2.66 \\
\hline Cool & Almost Cool & 20 & 187 & 3.74 \\
\hline Creative & Moderate & 18 & 184 & 3.68 \\
\hline Fun & Moderate & 17 & 176 & 3.52 \\
\hline Impressive & Moderate & 21 & 175 & 3.50 \\
\hline Interesting & Interesting & 19 & 200 & 4.00 \\
\hline Irritating & Moderate & 22 & 129 & 2.58 \\
\hline Lost & Less Lost & 16 & 112 & 2.24 \\
\hline Neat & Moderate & 21 & 154 & 3.08 \\
\hline Necessary & $\begin{array}{c}\text { Almost } \\
\text { Necessary }\end{array}$ & 19 & 189 & 3.78 \\
\hline Professional & $\begin{array}{c}\text { Almost } \\
\text { Professional }\end{array}$ & 23 & 201 & 4.02 \\
\hline Refreshing & Moderate & 21 & 178 & 3.56 \\
\hline Satisfied & $\begin{array}{c}\text { Almost } \\
\text { Satisfied }\end{array}$ & 20 & 174 & 3.48 \\
\hline Simple & $\begin{array}{c}\text { Almost } \\
\text { Simple }\end{array}$ & 16 & 190 & 3.80 \\
\hline Troublesome & Moderate & 16 & 106 & 2.12 \\
\hline User-Friendly & User-Friendly & 19 & 196 & 3.92 \\
\hline Waste of Time & $\begin{array}{c}\text { Not Waste of } \\
\text { Time }\end{array}$ & 22 & 108 & 2.16 \\
\hline & & & & \\
\hline
\end{tabular}

\section{- Product C: Screencast (Linear Video with No Visual Effects)}

Table VI shows almost the same results with Product B, though this type of production style did receive a tad off balance of 'moderate' response from students, in which is a bit higher compared to Product B's outcome. Even so, the results still justify that this type of production style also does not quite so manage to trigger the positive feelings among the students involved as they also almost inclined to feel moderate, with sixteen out of twenty-five feelings have resulted in Moderate level, thus, confirming the average influence of affective value in Product C: Screencast (Linear Video with No Visual Effects).

TABLE VI: PRODUCT C- SCREENCAST (LINEAR VIDEO WITH NO VISUAL EFFECTS)

\begin{tabular}{|c|c|c|c|c|}
\hline \multicolumn{5}{|c|}{ Results Generated from Descriptive Analysis Frequency } \\
\hline $\begin{array}{c}\text { Types of } \\
\text { Feelings }\end{array}$ & Level & $\begin{array}{c}\text { Frequency of } \\
\text { Respondents }\end{array}$ & $\begin{array}{c}\text { Total } \\
\text { Rating } \\
\text { Scale }\end{array}$ & $\begin{array}{c}\text { Mean } \\
\text { Value } \\
\text { (N) }\end{array}$ \\
\hline Annoying & $\begin{array}{c}\text { Less } \\
\text { Annoying }\end{array}$ & 17 & 107 & 2.14 \\
\hline Appealing & Moderate & 18 & 163 & 3.26 \\
\hline Attractive & Moderate & 23 & 162 & 3.24 \\
\hline Awkward & Moderate & 20 & 134 & 2.68 \\
\hline Boring & Moderate & 18 & 139 & 2.78 \\
\hline Convenient & Moderate & 22 & 177 & 3.54 \\
\hline Comfortable & Moderate & 24 & 178 & 3.56 \\
\hline Comprehended & Moderate & 32 & 155 & 3.10 \\
\hline Confusing & Moderate & 19 & 145 & 2.90 \\
\hline Cool & Almost Cool & 19 & 189 & 3.78 \\
\hline Creative & $\begin{array}{c}\text { Almost } \\
\text { Creative }\end{array}$ & 22 & 186 & 3.72 \\
\hline
\end{tabular}

\begin{tabular}{|c|c|c|c|c|}
\hline Fun & Less Fun & 13 & 157 & 3.14 \\
\hline Impressive & $\begin{array}{c}\text { Almost } \\
\text { Impressive }\end{array}$ & 16 & 181 & 3.62 \\
\hline Interesting & $\begin{array}{c}\text { Almost } \\
\text { Interesting, } \\
\text { Interesting }\end{array}$ & 14 & 180 & 3.60 \\
\hline Irritating & Moderate & 25 & 145 & 2.90 \\
\hline Lost & Moderate & 20 & 125 & 2.50 \\
\hline Neat & Moderate & 26 & 156 & 3.12 \\
\hline Necessary & Moderate & 18 & 175 & 3.50 \\
\hline Professional & Professional & 19 & 200 & 4.00 \\
\hline Refreshing & Moderate & 20 & 160 & 3.20 \\
\hline Satisfied & Moderate & 21 & 173 & 3.46 \\
\hline Simple & Simple & 16 & 188 & 3.76 \\
\hline Troublesome & Moderate & 21 & 126 & 2.52 \\
\hline User-Friendly & Moderate & 15 & 175 & 3.50 \\
\hline Waste of Time & $\begin{array}{c}\text { Not Waste of } \\
\text { Time }\end{array}$ & 27 & 94 & 1.88 \\
\hline
\end{tabular}

\section{HYPOTHESIS RESULTS}

The One-Way ANOVA was used to analyse the condition of mean value between Product A, Product B, and Product C. The reason of analysing using the One-Way ANOVA is to determine the significant difference in the mean condition between the product groups and support the hypothesis. Referring to the One-Way ANOVA, the sig. value between Product A, Product B, and Product C is 0.121 in which the value is far greater than the standard significance of 0.05 , hence the probability of something occurred is by chances and not because of independent variable's manipulation. The mean condition of Affective Value: Product A $(\mathrm{M}=3.35)$, Product B $(M=3.19)$, Product $C(M=3.18)$ and the $N=150$ respondents. $\mathrm{M}$ is the Mean value and $\mathrm{N}$ is the total number of respondents.

The $\mathrm{H}_{\mathrm{x}}$ is Null Hypothesis while $\mathrm{H} 1_{\mathrm{x}}$ is the Alternative Hypothesis. The p-value in One-Way ANOVA is a probability of frequent occurrence with 0.05 is the standard number of sig. value. If the $p$-value is equal or less than 0.05 , the value depicted that there is a statistically significant difference in mean condition between the Product A, Product $\mathrm{B}$, and Product $\mathrm{C}$, whereas, if the $p$-value is more than 0.05 , the value depicted that there is no statistically significant difference between the three products. Hence the difference Mean value is likely altered due to chances and not by manipulation.

Hypothesis A: Affective Value in Production Style

$\mathrm{H}_{1}$ : Affective value based on students' feelings were not affected in response to the production style.

$\mathrm{H} 1_{1}$ : Affective value based on students' feelings were affected in response to the production style.

TABLE VII: ANALYSIS RESULTS

\begin{tabular}{lllr}
\hline & & Sig. \\
\hline Pair 1 & Product A: & Product B: Green Screen & 0.215 \\
& IVML & Product C: Screencast & 0.147 \\
\hline \multirow{2}{*}{ Pair 2 } & Product B: & Product A: IVML & 0.215 \\
& Green Screen & Product C: Screencast & 0.978 \\
\hline Pair 3 & Product C: & Product A: IVML & 0.147 \\
& Screencast & Product B: Green Screen & 0.978 \\
\hline
\end{tabular}

Following the analysis results generated above in Table VII, the Pair 1 sig. value $=0.215$ between Product A: IVML 
condition and Product B: Green Screen condition, whereas the sig. value $=0.147$ between the Product A: IVML condition and Product C: Screencast condition. The Pair 2 sig. value $=0.215$ between Product B: Green Screen condition and Product A: IVML condition, whereas the sig. value = 0.978 between Product B: Green Screen condition and Product C: Screencast condition. The Pair 3 sig. value = 0.147 between Product C: Screencast condition and Product A: IVML condition, whereas the sig. value $=0.978$ between Product C: Screencast condition and Product B: Green Screen condition. All the three pairs mentioned thereof produce results where the $p$-values have a greater amount than the standard significance level of 0.05 value. Since the Sig. value $>0.05$ then the results conclude that there is no statistical difference between the Mean number of the three production styles. Hence, the Alternative Hypothesis $\left[\mathrm{H} 1_{1}\right]$ is rejected and Null Hypothesis $\left[\mathrm{HO}_{1}\right]$ is accepted wherein the Affective Value based on students' feelings were not affected in response to the production style. The variance of a mean condition in feelings is likely due to chances and not because of production style impact. In other words, the students happened to be more positively inclined toward Product A: IVML (Non-Linear with Visual Effects) in comparison with the other two products.

Though the One-Way ANOVA presented the mean condition of students' feelings response occurred are by prospects, however, the Product A: IVML (Non-Linear with Visual Effects) production style could encourage and motivate students to self-determined learning. According to the Descriptive Statistics Analysis Frequencies results, most students feel motivated to utilize the educational video if instructors considered the aesthetic value of visual design and the provide feature to select the topic (non-linear) within one single video timeline.

\section{CONCLUSION}

Finally, it can be concluded that the students have diverse feelings response concerning affective value perspective toward educational video production style. To sum up, producing an educational video with a non-linear video sequence and aesthetic visual design concept manage to generate an active and positive emotional response from the students. Three different production styles were used in the test, Product A: IVML (Non-Linear with Visual Effects), Product B: Green Screen (Linear with Visual Effects) and Product C: Screencast (Linear with No Visual Effects). Through the Kansei Engineering method, the results concluded that students are more inclined to have a positive response toward Product A: IVML (Non-Linear with Visual Effects). This type of production style manages to trigger students' feelings and they are most responsive emotion stimulation when compared to the other two groups of respondents under Product B: Green Screen (Linear with Visual Effects) and Product C: Screencast (Linear with No Visual Effects). The study also shows that 105 students out of 150 students feel positively motivated if the aesthetic value is included in video design whilst 45 students remain passive. And compared to the traditional linear video style, although the 46 students' feelings were passive even if the control to jump from one topic to another in one single video timeline are featured, however, there are 106 students out of 150 students feel positively motivated. Foremost, the findings reveal the probabilities of correlation between learners' engagement feelings (affective value) and educational video production style, a context that has not yet been discussed.

\section{CONFLICT OF INTEREST}

The authors declare no conflict of interest.

\section{AUTHOR CONTRIBUTIONS}

Nur Faraha Bte Hj. Mohd. Naim conducted the research, analyzed the data and wrote the paper. Ag. Asri Ag. Ibrahim supervised, reviewed and approved the final version.

\section{ACKNOWLEDGMENT}

The authors would like to express their gratitude to Universiti Malaysia Sabah, Universiti Malaysia Pahang and Universiti Malaysia Perlis.

\section{REFERENCES}

[1] Malaysian watch more YouTube than anyone else in the world. (2016). New Straits Times. [Online]. Available: https://www.nst.com.my/news/2016/02/129141/msians-watch-more-y outube-anyone-else-world

[2] I. Vieira, A. P. Lopes, and F. Soares, "The potential benefits of using videos in higher education," in Proc. 6th International Conference on Education and New Learning Technologies, 2014, pp. 750-754.

[3] A. Hansch, L. Hillers, K. McConachie, C. Newman, T. Schildhauer, and P. Schmidt. (2015). Video and online learning: Critical reflections and findings from the field. HIIG Discussion Paper Series. [Online]. 2. p. $11 . \quad$ Available: https://papers.ssrn.com/sol3/papers.cfm?abstract_id=2577882

[4] P. Fitzgibbon, "Challenges of video-conferencing teaching and effective teaching methods," The Turkish Online Journal of Educational Technology-TOJET, vol. 2, no. 3, pp. 32-33, 2003.

[5] D. Denning. Video in theory and practice: Issues for classroom use and teacher video evaluation. [Online]. Available: https://www.academia.edu/4666293/Video_in_Theory_and_Practice_ Issues_for_Classroom_Use_and_Teacher_Video_Evaluation

[6] C. Brame. (2015). Center for teaching: Effective educational videos [Online]. Available: https://cft.vanderbilt.edu/guides-sub-pages/effective-educational-vide os/

[7] N. A. Buzzetto-More, "An examination of undergraduate student's perceptions and predilections of the use of YouTube in the teaching and learning process," Interdisciplinary Journal of E-Learning and Learning Objects, vol. 10, pp. 28-30, 2014.

[8] K. J. Kies, R. C. Williges, and M. B. Rosson, "Evaluating desktop video conferencing for distance learning," Computers Education, vol. 28, no. 2, p. 85, 1997.

[9] Kaltura: Fifth annual state of video in education. (2018). [Online]. p. 23. Available:

https://corp.kaltura.com/wp-content/uploads/2018/07/The_State_of_V ideo_in_Education_2018.pdf

[10] S. L. Cresswell, W. A. Loughlin, M. J. Coster, and D. M. Green, "Development and production of interactive videos for teaching chemical techniques during laboratory sessions," Journal of Chemical Education, vol. 96, no. 5, p. 1035, 2019.

[11] M. Nagamachi, N. Imanishi, T. Ishizawa, and S. Yano, "A successful statistical procedure on Kansei engineering products," in Proc. 11th QMOD Conference, 2008, p. 988.

[12] METI. (2014). Kansei initiative firm materialistic fulfillment to emotional fulfillment. [Online].Available: http://www.meti.go.jp/english/policy/mono_info_service/mono/kansei 2009/

[13] P. Levy, "Beyond Kansei engineering: The emancipation of Kansei design," International Journal of Design, vol. 7, no. 2, p. 83, 2013.

[14] M. C. Kee, J. C. Chwen, and S. T. Chee, "Kansei engineering concept in instructional design: A novel perspective in guiding the design of 
instructional materials," in Proc. 5th International Cyberspace Conference on Ergonomics, 2008, p. 1.

[15] H. Adnan and F. Redzuan, "Evaluating students' emotional response in video-based learning using Kansei engineering," in Proc. 4th International Conference on User Science and Engineering (i-USEr), 2016, p. 1.

[16] S. Zubir and F. Redzuan, "Evaluating students' emotional response in mobile-learning using Kansei engineering," in Proc. 7th International Conference on Kansei Engineering and Emotion Research, 2018, p. 801

[17] H. Taherdoost, S. Shamsul, and N. Jalaliyoon, "Exploratory factor analysis; concepts and theory," Advances in Applied and Pure Mathematics, p. 377, 2014.

[18] N. U. Hadi, N. Abdullah, and I. Sentosa, "An easy approach to exploratory factor analysis: Marketing perspective," Journal of Educational and Social Research, vol. 6, no. 1, p. 216, 2016.

Copyright $\odot 2020$ by the authors. This is an open access article distributed under the Creative Commons Attribution License which permits unrestricted use, distribution, and reproduction in any medium, provided the original work is properly cited (CC BY 4.0).

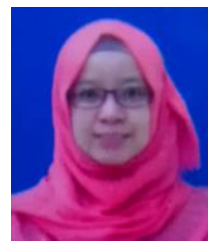

Nur Faraha Bte Hj. Mohd. Naim received her master of science (information technology) from UMS in 2016 and bachelor's degree in multimedia application (BMM hons.) from UUM in 2008

She is a graduate fellow and a Ph.D. student in Universiti Malaysia Sabah. Her research interest is in mobile learning, Kansei engineering, and human-computer interaction.

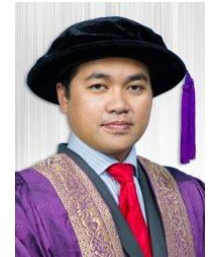

Ag. Asri Ag. Ibrahim received his doctor of philosophy (electronics) from the University of York in 2008, master of computer science from UM in 1999 and bachelor's degree in computer science (hons.) also from UM in 1998.

Assoc. Prof. Dr. Ag. Asri Ag. Ibrahim is a director in the Department of Information Technology and Communication (JTMK), Universiti Malaysia Sabah. His research interest is in sonification, Kansei engineering, human-computer interaction, and usability. He had 27 journals, 40 Proceedings, 12 Books and 4 General Publication published. He is also an expert in Human-Computer Interaction (HCI) and other ICT Applications N.E.C. 